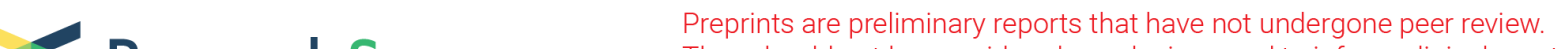 Research Square They should not be considered conclusive, used to inform clinical practice, or referenced by the media as validated information.
}

\section{Reducing LGBTQ+ adolescent mental health inequalities: A realist review of school-based interventions}

Elizabeth McDermott ( $\nabla$ e.mcdermott.1@bham.ac.uk)

School of Social Policy, University of Birmingham

Alex Kaley

Faculty of Health and Medicine, Lancaster University

Eileen Kaner

Population Health Sciences Institute, Newcastle University

Mark Limmer

Faculty of Health and Medicine, Lancaster University

Ruth McGovern

Population Health Sciences Institute, Newcastle University

Felix McNulty

Faculty of Health and Medicine, Lancaster University

Rosie Nelson

School of Sociology, Politics, and International Studies, University of Bristol

Emma Geijer-Simpson

Population Health Sciences Institute, Newcastle University

Liam Spencer

Population Health Sciences Institute, Newcastle University

\section{Research Article}

Keywords: Lesbian, Gay, Bisexual, Transgender, Youth, Schools, Education, Mental Health Inequalities, Intervention

Posted Date: February 1st, 2022

DOI: https://doi.org/10.21203/rs.3.rs-1280351/v1

License: (c) (1) This work is licensed under a Creative Commons Attribution 4.0 International License.

Read Full License 


\section{Abstract}

Background: Globally, research indicates that LGBTQ+ young people have elevated rates of poor mental health in comparison to their cisgender heterosexual peers. School environment is a key risk factor and is consistently associated with negative mental health outcomes for LGBTQ+ adolescents, suggesting a need to intervene to affect change within the school environment. The aim of this review was to examine how, why, for whom and in what context school-based interventions prevent or reduce mental health problems in LGBTQ+ adolescents?

Method: A realist review was conducted utilizing the seven-step published protocol $(1,2)$. The review focused on all types of school-based interventions that impacted on LGBTQ+ adolescent mental health. All study designs were included. The search strategy involved comprehensive electronic database searches and additional complementary search strategies (hand searching, citation tracking). Studies were subject to an inclusion criteria and quality appraisal. Those included in the review where subject to data extraction under defined fields of context, mechanism and outcome and synthesized to produce a programme theory.

Results: In total, 4,911 titles and abstracts were screened, and 125 full papers reviewed, with 17 studies included in the final review. The review found 8 intervention components were necessary for school-based interventions to address LGBTQ+ pupil's mental health: affirmative visual displays; external signposting to LGBTQ+ support; stand-alone input; school-based LGBTQ support groups; curriculum-based delivery; staff training; inclusion policies; trusted adult to talk to. Explaining how an intervention worked is complex and the programme theory developed emphasises the multiple causal pathways (e.g., psychological, behavioural, emotional, environmental, social) that operate to reduce poor mental health.

Conclusions: We identified relatively few school-based interventions for this population group. The developed programme theory indicates that 'to work' school-based interventions must have a 'wholeschool' approach that addresses specifically the dominant cis-heteronormative school environment and hence the marginalisation, silence, and victimization that LGBTQ+ pupils experience. We require more research on school interventions to reduce the inequalities in mental health in LGBTQ+ youth. We need to understand the underlying mechanisms that produce this inequality to design successful school public mental health interventions.

\section{Background}

There are considerable mental health inequalities between lesbian, gay, bisexual, trans and queer/questioning (LGBTQ+) young people and their cisgender heterosexual peers (1). Systematic reviews and meta-analyses consistently report a higher prevalence of depression, self-harm, suicidal ideation and attempts, and problematic substance use in LGBTQ+ youth compared to cis-heterosexual youth (2-6). A recent meta-analysis of studies comparing suicidality in youth found that compared to cisgender and heterosexual youth, trans youth were six times, bisexual youth five times and lesbian and 
gay (LG) youth 4 times more likely to report a history of attempted suicide (7). The restrictions due to Covid-19 have also had a disproportionate impact on LGBTQ+ young people's mental health (8), and trans and gender diverse youth have been more effected by the pandemic than cis youth (9).

School climate is a leading predictor of students' emotional and behavioural outcomes (10). School climate encompasses all elements of the school experience for young people, including quality of teaching and learning, school community relationships, school organisation, and the institutional and structural features of a school environment. This contributes to the quality of interactions for students, teachers and parents, and reflects the norms, values and goals, which represent the educational and social objectives of the school (11). School climate affects students' adaptive psychosocial adjustment (12), mental health outcomes $(13,14)$, and self-esteem (15). Further, it has been specifically associated with LGBTQ+ youth's experience of mental health problems, such as depression and suicidality (16). A UK-based study, which surveyed over 7,000 young people aged 16 to 25 found that most young LGBTQ+ people feel that their time at school is affected by hostility or fear, with consequences such as feeling left out, achieving lower grades, and having to move schools. Most reported that their school supported its pupils badly in respect of sexual orientation or gender identity (17).

A 2021 scoping review and found that peer victimisation, bullying and safety concerns are prevalent for transgender young people within the secondary schooling environment (18), and studies consistently reported that each of these three factors are related to negative mental health outcomes. The 2016 UNESCO Out in the Open (19) report identified homophobic, biphobic and transphobic (HBT) violence in schools as a global problem, and young people who are perceived not to conform to prevailing sexual and gender norms, including those who are LGBTQ+ identified, as most vulnerable. The report concluded that a 'comprehensive approach' that involves the whole education sector was the most effective means of addressing the issue. However, only three countries had conducted a large-scale formal evaluation of interventions to tackle HBT violence in schools: the Netherlands, USA, and the UK.

In the UK the intervention to tackling HBT bullying in schools $(20,21)$ has been evaluated nationally $(21)$. This research remains one of the only evaluations of an intervention that seeks to tackle this issue (nationally and globally). A key finding from the evaluation was that for anti-HBT bullying initiatives to be successful they needed to be part of a 'whole school' approach (22). The 'whole school' approach addresses HBT bullying across and through involvement of the entire school rather than being limited to one area of activity (21). The 'whole school' approach attempts to move away from individually oriented approaches that focus on punishing single actors (e.g., bullies), and instead moves to, for example, creating more inclusive curricula and more positive LGBTQ+ representation. Formby (23) argues that a narrow focus on HBT bullying does not address the multi-levelled approach needed to challenge the dominant cis-heteronormative culture of schools and create an LGBTQ+ inclusive environment. National policy both in the UK and US has tended to have a limited focus on HBT-bullying in schools that concentrates on individual actors and conceals the systemic and pervasive gender and sexual minority inequalities of the wider school climate $(24,25)$. 
Significantly, the UK evaluation of the 'whole-school' intervention to tackle HBT-bullying in schools did not evaluate the impact of the intervention on pupil mental health (21). A 2012 systematic review conducted on the impacts of school climate and safe school interventions/programmes on LGBTQ+ youth outcomes (26) indicated that effective interventions could be grouped according to three common themes: 1) Inclusive programs including support groups (e.g. gay-straight alliances), teacher training programs, and community or student diversity training; 2) Policies encompassing anti-discrimination policies for students and faculty, and clear and enforceable anti-harassment policies; 3 ) A supportive environment constituting of safe school policies, school board support of inclusive curriculum, available supportive staff, inclusive class discussions about LGBTQ+ issues, and peer acceptance. The authors conclude that safe schools with unclear or unstable policy and programs resulted in more student mental health problems e.g. depression, anxiety (26).

However, what is clear from this systematic review (21) is that the evidence is sparse and based mainly in US and Canada. More importantly, the explanations for why these interventions may improve LGBTQ+ youth mental health have been approximated rather than investigated robustly. This has repercussions for developing interventions to tackle school climate because we do not know what works, for whom, and in what context. That is, we do not understand the mechanisms that underpin the impact of school environment on LGBTQ+ youth mental health or their relationship to different contexts, and this restricts the transferability of interventions to a variety of educational contexts. Taking a public health approach to address this paucity of evidence, this realist review aimed to develop a theoretical understanding of the processes through which interventions within educational settings may prevent or reduce LGBTQ+ adolescents mental health inequalities. The review had two research questions: 1) What evidence exists that school-based interventions can prevent or reduce mental health problems in LGBTQ+ adolescents? 2) How, why, for whom and in what context may school-based interventions prevent or reduce mental health problems in LGBTQ+ adolescents?

\section{Method}

The realist review method is a theory driven approach to systematic reviews that has been developed for complex social interventions where the experimental paradigm of the randomized control trial may be an inappropriate methodology for producing evidence $(27,28)$. The realist review method uses relevant theory, causal models, and empirical data to establish how a public health intervention causes particular outcomes in what circumstances and for whom. Therefore, a realist review methodology is used to explain why interventions have failed, as well as why they are successful; it provides theoretical explanations for 'what works, for whom, under what circumstances, how and why?' (27).

The realist research tradition is premised upon an ontological perspective that social reality is interpretative and social actors (human beings) evaluate social reality (28). From a realist perspective, 'to understand how outcomes are generated, the role of external reality and human action need to be incorporated' (29). A realist approach attempts to identify the underlying theories that explain the patterns in the way individuals make similar choices within particular intervention conditions (demi-regularities). In 
other words, a realist perspective identifies the context within which mechanisms (underlying processes) generate the outcomes of interest (e.g., mental health).

The realist review method is appropriate when considering complex interventions which consist of many components and are contingent upon the behaviours and choices of those they seek to benefit. In addition, this method is used when there is little evidence on the effectiveness or acceptability of interventions $(30)$ and/or the literature is heterogenic $(31,32)$. The realist review methodology follows the same rigorous format as aggregative systematic reviews but the synthesis of the research is focussed on theory generation and specifically aims to broaden understanding of particular interventions rather than testing causal hypotheses (33). The key analytic process in a realist review involves the development of a programme theory that explains how and why and in what context the intervention will produce its desired objectives. We followed the establish seven-step realist review protocol $(28,29)$ and publication standards (27).

\subsection{Scoping the literature}

The aim of the scoping literature search was to assess the available published literature on school-based interventions aimed at preventing LGBTQ+ youth mental health problems. The results indicated a sufficient evidence base, highlighting specific features consistently contributing to a positive school climate for LGBTQ+ youth such as anti-discrimination policies (34-36), gay-straight alliances $(16,34,37)$, LGBTQ+ inclusive curriculum (38), and peer and teacher support in schools $(16,39)$.

\subsection{Developing the initial theory}

Emmel et al. (40) highlight the importance of identifying the right theories at the start of a realist project to frame the study. Public health interventions are complex and there is a plethora of possible theories. At the start of the review we identified, through expertise in the research team, six existing Middle Range Theories (MRTs) (41) that explain why there is elevated poor mental health in LGBTQ+ populations. These theories were from a range of disciplines and therefore had a variety of perspectives these were: Johnson (2015) psychosocial (42); Meyer (2003), Hatzenbuehler (2009) and Riggs \& Treharne (2017) all psychology (43-45); Cover (2012) and McDermott \& Roen (2016) both queer theory $(46,47)$. In addition, the initial theory was informed by the two UK national reports on the 'whole-school approach' to tackling HBT bullying in schools $(20,21)$. This intervention was delivered to over 900 schools in the UK. The whole-school approach involves seven identified programme elements: affirmative visual displays; external signposting to LGBTQ+ support; stand-alone input; school-based LGBTQ support groups; curriculum-based delivery; staff training; and inclusion policies. The evaluation highlighted that these seven programme elements were important to ensuring a whole-school approach to tackling anti-HBT bullying.

Close stakeholder engagement from the outset is recommended in realist reviews (48) and five young LGBTQ+ people (aged between 15 and 22) were recruited to participate in a Youth Advisory Group to support the research. The aim of involving LGBTQ+ young people was to help to develop the initial theory 
and ensure this was informed by stakeholder perspectives. The young people were treated as full members of the research team and were employed by the University as paid researchers. To develop the initial theory, LGBTQ + young people attended interviews \& focus groups, and vignettes were used to explore why (and in what context) particular school-based interventions prevent or reduce mental health problems in LGBT adolescents. Figure 1 outlines the Initial Theory developed from the Middle Range Theories, LGBTQ+ Youth Advisory Group, the empirical papers from the scoping review and the two national reports of the UK anti-HBT bullying intervention. This Initial Theory was then used to inform the realist review with the expectation that it would be refined via the review synthesis process to produce a Programme Theory.

\section{INSERT FIGURE 1 HERE}

\subsection{Search strategy}

Multiple search strategies were used to locate relevant evidence from 1999 to March 2021. The start date of the review was January 1999 to reflect the greater liberalisation in legislation, policy, and practice regarding LGBTQ+ populations worldwide. Expert informants advised that before this date, significant and relevant LGBTQ+ school-based research was not available. The social and cultural context of LGBTQ+ people's lives in the West has changed dramatically in the last 20 years and therefore research before this 'modern' era is likely to be out-dated. Systematic electronic searches were conducted for peerreviewed articles published in both discipline specific databases (PubMed, PsycINFO, Embase, ERIC, CINAHL), and multidisciplinary databases (Web of Science, Google scholar, Scopus). Expert consultation, forward citation tracking and hand-searching were utilized to supplement the electronic database search. The search terms were divided into five main domain categories: i) sexual orientation and gender identity; ii) age; iii) education; iv) mental health and wellbeing v) intervention (see Appendix 1).

\subsection{Inclusion and exclusion criteria}

Studies were eligible for inclusion if they were published in English and evaluated: i) changes to the educational setting; ii) the effect of the changes on mental health outcomes; iii) LGBTQ+ young people (see Table 1). The mental health outcomes included direct measures of mental health e.g., anxiety, depression and suicidality, measures associated with mental health e.g., self-esteem, and measures that are important to mental resilience \& wellbeing e.g., coping, agency, affect regulation. The inclusion/exclusion criteria were applied by four researchers for their eligibility in the review. Regular meetings were held to discuss the application of the criteria and to improve reliability. 
Table 1

Inclusion/exclusion criteria

\begin{tabular}{|c|c|c|}
\hline & Inclusion & Exclusion \\
\hline \multirow[t]{3}{*}{ Population } & \multirow{3}{*}{$\begin{array}{l}\text { LGBTQ+ youth aged between } 10 \text { and } 18 \text { years } \\
\text { old }\end{array}$} & - Non-LGBTQ+ youth \\
\hline & & - LGBTQ+ youth under 10 years old \\
\hline & & $\begin{array}{l}\text { - LGBTQ+ youth aged } 19 \text { years and } \\
\text { over }\end{array}$ \\
\hline \multirow[t]{2}{*}{ Intervention } & $\begin{array}{l}\text { - Measured changes to formal \& statutory } \\
\text { educational environment }\end{array}$ & \multirow{2}{*}{$\begin{array}{l}\text { - Interventions delivered in non- } \\
\text { formal \& non-statutory educational } \\
\text { settings }\end{array}$} \\
\hline & $\begin{array}{l}\text { - Interventions within formal \& statutory } \\
\text { educational settings }\end{array}$ & \\
\hline \multirow{2}{*}{$\begin{array}{l}\text { Study } \\
\text { design }\end{array}$} & - All empirical study designs & $\begin{array}{l}\text { - Papers not empirical based or } \\
\text { theory relevant }\end{array}$ \\
\hline & - Relevant theory-based papers & $\begin{array}{l}\text { - Prevalence \& observational studies } \\
\text { where no intervention }\end{array}$ \\
\hline \multirow[t]{4}{*}{ Outcomes } & $\begin{array}{l}\text { - Poor mental health e.g. anxiety, suicidality, } \\
\text { depression }\end{array}$ & \multirow[t]{4}{*}{$\begin{array}{l}\text { - No mental health outcomes } \\
\text { reported }\end{array}$} \\
\hline & $\begin{array}{l}\text { - Positive mental health including wellbeing, } \\
\text { resilience, life satisfaction }\end{array}$ & \\
\hline & $\begin{array}{l}\text { - Psychological factors associated with } \\
\text { mental health e.g. self-esteem, coping, affect } \\
\text { regulation }\end{array}$ & \\
\hline & $\begin{array}{l}\text { - Outcomes identified through self-report or } \\
\text { standardized assessment }\end{array}$ & \\
\hline Language & English & Any language other than English. \\
\hline Time frame & Published from 1999 & $\begin{array}{l}\text { Papers or document published } \\
\text { before } 1999\end{array}$ \\
\hline
\end{tabular}

INSERT Table 1 HERE

\subsection{Quality appraisal}

The appraisal of quality in realist reviews is conducted differently from conventional systematic reviews (28).This is due to the fact that realist review methodology rejects the 'hierarchy of evidence' with the randomised controlled trial (RCT) sitting at the top because RCTs focus on what works, and largely overlook the circumstantial factors influencing the effectiveness of an intervention $(28,49)$. Realist appraisal of studies uses two main criteria to decide whether the study will be considered in the synthesis: relevance and rigour (28). 
Firstly, studies were assessed on their relevance. Studies were deemed eligible if they could contribute to building or testing theories about educational interventions and how they may widen or reduce mental health inequalities amongst LGBTQ+ youth. Secondly, the methodological rigour of each individual study was judged to ascertain whether it was trustworthy and had sufficient weight to make a credible contribution to developing the intervention theory. We adapted a previously used realist review methodological appraisal criteria from Jagosh and colleagues (50) that asked 4 main questions: 1) Does the full-text paper describe the research setting? 2) Does the full-text paper indicate empirical research (i.e., that there is some description of methodology, methods, data collection and analysis)? 3) Does the full-text paper describe LGBTQ+ youth mental health outcome data? 4) Does the full-text paper describe an LGBTQ+ youth mental health intervention in an educational setting? These criteria were applied by four of the authors with regular meetings to discuss decisions.

\subsection{Data Extraction}

There is no fixed method of data extraction in realist reviews and Wong et al. (27) suggest that an eclectic and iterative approach to data extraction be adopted. We designed a data extract template and for each included study we extracted the study details, intervention type, context, mechanism, outcome. The data was extracted in 'conversation' with the Initial Theory (Figure 1) (51) and we recorded reflective notes on the data extraction process in relation to the main research question: How, why, for whom and in what context may school-based interventions prevent or reduce mental health problems in LGBTQ+ adolescents?

\subsection{Data synthesis}

The aim of the data synthesis was to refine the Initial Theory through realist synthesis methods to produce a Programme Theory. Early publications describing the realist review process contain little guidance about the synthesis stage (52) and more recent publications suggest that any appropriately selected and justified analytic techniques might be used (27). We have therefore drawn on Rycroft Malone et al's 2012 (52) methodological steps in developing a programme theory and Dalkin et al.'s 2015 (51) disaggregation of the concept of mechanism into two parts: i) intervention resources; ii) participants' reasoning.

A fundamental building block of realist explanation and developing a programme theory is generating causal links between context, mechanism, and outcome (CMOs). CMOs are theories of causality, a realist approach argues that we cannot observe causal patterns alone and theory (mechanisms) explain the patterns and why there is a relationship. We tabulated the CMOs for each of the included papers, and then integrated these with the Initial Theory we had developed. We used the six identified MRTs (42-47) to develop the causal pathways, these theories were used to deepen the explanations of why each of the intervention components might reduce poor mental health in LGTQ+ young people. We also ran a workshop with the LGBTQ+ Youth Advisory Group to enhance this thinking. Through the identification of potential CMOs we then refined the Initial Theory to produce a programme theory about why schoolbased interventions may work to reduce LGBTQ+ adolescents mental health inequalities. 


\section{Results}

\subsection{Search results}

The results of the searches, screening and appraisal process are displayed in the PRISMA flow chart (Figure 2). The search criteria applied in electronic databases returned $n=6,597$ results, which after duplicates were removed left $n=4,911$ potentially eligible articles. After title and abstract screening, there were $n=125$ articles which were included in the next stage. The full-text screening, appraisal, and expert review process eliminated $n=56$ articles in total, and resulted in $n=69$ relevant articles, $n=15$ of which were empirical papers included in the final realist synthesis.

\section{FIGURE 2 HERE}

Delays due to Covid-19 restrictions meant that in March 2021, additional searches were run using Web of Science, PsycINFO and PubMed databases (September 2019 to March 2021). These searches returned $\mathrm{n}=76$ results, which after duplicates were removed left $\mathrm{n}=30$ articles. After title and abstract screening, there were $n=4$ articles which were screened at full-text with expert review, and consequently $n=2$ additional empirical papers were included in the final realist synthesis. The total number of papers included from the two searches were $n=17$ (see Table 2). 
Table 2

Included Empirical literature $(\mathrm{n}=17)$

Bopp et al., 2004 (53)

Burk et al., 2018 (54)

Craig et al., 2014 (55)

Goodenow et al., 2006 (56)

Gunderson et al., 2021 (57)

Hatzenbuehler \& Keyes, 2013 (58)

Hatzenbuehler et al., 2014 (59)

Heck, 2013 (60)

Heck, 2015 (61)

Lapointe \& Crooks, 2018 (62)

Lindquist, 2016 (63)

Poteat et al., 2015 (64)

Poteat et al., 2016 (65)

Poteaet et al., 2021 (66)

Saewyc et al., 2014 (67)

Sandfort et al., 2010 (68)

Zhang et al., 2018 (69)

Table 2 HERE

\subsection{Study characteristics}

The majority of the 17 empirical studies included $(n=14)$ were published from 2013 onwards, indicating a growing field of research. None of the studies were conducted in the UK, with only one study (Netherlands) based outside of North America (USA $n=12$; Canada $n=4$ ). The most frequently considered sample characteristics were sexuality, age (range 12 to 20 years), gender, and ethnicity e.g., Latinx, Pacific Island and First Nations peoples, but Asian ethnicities were less represented. Most included studies involved survey questionnaires $(n=12)$, there were few qualitative designs $(n=2)$, mixed methods $(n=1)$, and pilot programmes $(n=2)$. However, most of these studies also drew on very large sample sizes (e.g., $55,599)$, with data gathered using validated tools.

The interventions most frequently considered in the included studies were Gay-Straight Alliances $(n=7)$, followed by health-based programmes $(n=4)$. Some studies explored GSAs in isolation $(n=3)$, whilst other interventions considered school policies and climate $(n=2)$, as well a film-based intervention $(n=1)$. The 
most frequently considered mental health outcome in the included studies was suicidality $(n=8)$, other outcomes were self-esteem ( $n=3)$ and coping $(n=2)$. Wellbeing, depression and anxiety, purpose in life, mastery, and sense of agency were also measured in some studies (see Appendix 2 for included studies characteristics).

\subsection{Programme Theory}

The final programme theory detailing the context-mechanism-outcome configurations for school-based interventions is outlined in Figure 3. Explaining why and how an intervention may have an impact on mental health is complex (and under-researched). To help make explicit and theorise 'what changes' and 'how it changes' as a result of an intervention, we developed Dalkin's (2015) dual concept of mechanism intervention resource and response mechanism (51) - and added a new third mechanism factor which we called the 'vector of change'. The inclusion of the new concept of 'vector of change' was to capture multiple causal pathways at which a mental health intervention may work e.g., psychological, behavioural, emotional, environmental, social.

\section{FIGURE 3 HERE}

It is important to note that the Programme Theory was developed as a 'whole-school approach' but the context in which the intervention was delivered was often under-reported and unexamined in the included empirical studies. We found three key contextual factors were important to the success of school-based interventions that improved LGBTQ+ young people's mental health. Firstly, a positive baseline (before intervention delivery) school culture towards sexual and gender diversity was highlighted. Secondly, the presence of a member of education staff or pupil who 'championed' LGBTQ+ pupil equality and worked toward achieving a LGBTQ+ inclusive environment. Thirdly, where interventions were implemented in schools with national legal, policy and economic directives that specifically addressed LGBTQ+ equality, they were more likely to be successful in improving LGBTQ+ pupil mental health outcomes.

Mechanism 1 in the Programme Theory (Figure 3) focused on the intervention resources and contained 8 components that aimed to reduce LGBTQ+ adolescent poor mental health burden. The original Initial Theory contained seven components, we have added an eighth component, 'a trusted adult to talk to', that the included studies suggested was important to reducing poor mental health. Across the literature we reviewed, there was evidence that a combination of these components was most likely to be successful in reducing the poor mental health of LGBTQ+ young people.

Mechanism 2 'vectors of change' in the Programme Theory addresses the multiple causal pathways (psychological, behavioural, emotional, environmental, social) at which a particular mental health intervention component may work. We identified 5 vectors of change through which the intervention component may work: the school environment and culture becoming more LGBTQ+ inclusive; relationships and interactions between individuals (both pupil to pupil and staff and pupil) becoming less hostile and more connected; individual behaviours and actions changing; individual LGBTQ+ pupils thoughts and beliefs about the self-improving e.g. self-esteem, positive identity orientation; individual 
affect, feelings \& emotions becoming less problematic. The literature suggested that these 5 vectors of change may co-occur.

Mechanism 3 'cognition' or 'response mechanism' explains how the intervention effects the individual actor's reasoning and response to intervention components. Here we have identified the importance of 'affirmation' of LGBTQ+ identities to improving self-esteem, self-acceptance, confidence, and validation. 'Agency' as a capacity to initiate and sustain actions regarding LGBTQ+ status, and 'Advocacy' as a process of empowerment to change school culture. 'Belonging' to the school and feeling included was an important factor in good mental health for LGBTQ+ pupils especially in reducing isolation and loneliness. Relatedly, school connectedness and feeling similar to others (peers and staff) improved mental health. 'Coping' this was both individual coping with hostility, invisibility or misgendering but also includes group problem solving. 'Recognition' of LGBTQ+ identity, the synthesis suggested, was important to validating LGBTQ+ young people within school. Feeling 'safe' and without fear was crucial to improving LGBTQ+ youth mental health. The final mechanism 'usualising' was the feeling that being LGBTQ+ was accepted and 'normal' in school culture. In our theoretical development, it was evident that these cognitive processes would co-occur and be inter-related.

Overall, the evidence suggested that interventions that seek to make the school environment more inclusive for LGBTQ+ young people can improve mental health outcomes by both reducing poor mental health e.g., suicidal feelings and depression, and increasing factors associated with good mental health e.g., self-esteem and coping. The Programme Theory we have developed attempts to elucidate the underpinning mechanisms that explain how and why these interventions may work to improve LGBTQ+ youth mental health.

\section{Discussion}

This realist review has developed a programme theory of how, why, for whom and in what context schoolbased interventions prevent or reduce mental health problems in LGBTQ+ adolescents. To improve the mental health of LGBTQ+ pupils i.e., for the intervention to 'work' school-based interventions must address specifically the marginalisation, silence, victimization, and misrecognition that LGBTQ+ pupils experience within the dominant cis-heteronormative school environment. The pervasiveness of learning in a school culture that excludes pupils whose sexual and gender is at odds with the dominant norms was noted by many scholars whose work contributed to our review. The literature we engaged with suggested that to change the school environment to improve LGBTQ+ pupils mental health requires a multi-level approach $(5,44)$ or in the UK, this has been termed the whole-school approach to LGBTQ+ school inclusivity $(19,21,23)$.

The strength of the whole-school approach is that the intervention aims to change the school environment at the structural, cultural, and individual level. This is because hostility, discrimination and bullying on the basis of perceived gender and sexual diversity does not arise purely from individuals or groups but rather reflects (and upholds) cis-heteronormativity (dominant norms surrounding gender as a 
binary and heterosexuality). Developing a LGBTQ+ inclusive school environment needs policies that specifically tackle HBT bullying and discrimination (in staff and pupils), and policies that promote equality across gender and sexual diversity. It includes staff training and support for implementing such policies and an inclusive curriculum, providing school resources for LGBTQ+ support and activism (along with allies) and ensuring there are school staff that LGBTQ+ pupils can talk to and trust. This all creates better relationships in school between staff and pupils where trust, care, belonging, connection, and confidence can flourish, and mental health can improve.

Across the literature we reviewed, scholars worldwide were struggling with similar difficulties in trying to understand the problem and provide solutions. The background for each paper was the marginalisation and stigmatisation of young LGBTQ+ lives, the impact that school life had on their mental health, and the dearth of appropriate school-based interventions aimed at generating an inclusive environment and improving mental health. Often, scholars noted the absence of policy attention to the matter of LGBTQ+ pupils' difficulties in schools. We need more research and datasets that can examine how best to address the school mental health of LGBTQ+ pupils. Our realist review exposed the limited evidence of the various contextual factors that may be important to the success of interventions. For example, does the ethnic composition of the school matter (probably yes)? Does religion? Or socioeconomic status? How should interventions be delivered and implemented? When and by who? Research of this nature requires both large datasets that better measure interventions and different mental health outcomes, but we also need qualitative research that explores how and why school culture can change.

The strength of our realist review is that it provides a baseline theoretical understanding for why and how school-based interventions might improve mental health for LGBTQ+ young people. Much of the literature we reviewed had limited data on how the interventions may or might not work, with some notable exceptions such as Saecyc at al. (5). A further strength of the Programme Theory is that it is drawn from a synthesis of empirical data from a range of disciplines (psychology, public health, sociology, social work), a national evaluation of a UK anti-bullying in schools' intervention, theories that explain LGBTQ+ youth mental health disparities and the perspectives of LGBTQ+ young people (Advisory Group).

However, the review is limited partially by the limitations of the empirical studies we were able to locate. Often scholars where relying on already existing data and 'matching' this with created variables. Consequently, there was a variation in the demographic characteristics reported, the terms used, and how different groups are categorised. The use of pre-existing large-scale surveys introduces a restrictive dynamic to the questions and ideas explored by the studies, potentially limiting the granularity of detail available for a realist review. As a consequence, there was not adequate evidence to fully plot the causal pathways and detail the generative causal connections. In addition, the included studies lacked an intersectional perspective on LGBTQ+ identities; particularly attention on the variation between lesbian, gay, bisexual, and transgender, and diverse gender identities, as well as other intersectional characteristics, such as ethnicity, poverty, rurality, and disability. Despite these limitations the realist review provides the first baseline theoretical understanding for why and how school-based interventions might improve mental health for LGBTQ+ young people. This is a starting point; it should now be 
developed through empirical refinement to improve understanding of the contextual factors in which successful school-based interventions are delivered and the causal pathways that reduce LGBTQ+ pupil poor mental health.

\section{Conclusions}

There are mental health inequalities between LGBTQ+ young people and their cis-heterosexual peers. The Covid-19 pandemic has exacerbated this inequality and disproportionately impacted on the mental health of LGBTQ+ youth compared to cis-heterosexual youth (Kamal et al. 2020), and trans and gender diverse youth are more effected than cis-youth (Hawke et al. 2021). Fish and colleagues (2020) report that some LGBTQ+ youth felt more isolation due to loss of safer spaces at school such as supportive teachers and groups. The pandemic has heightened our awareness of the role of school in young people's lives and their mental health. The UK government has highlighted the need to address young people's mental health and the importance of anti-HBT-bullying to improving LGBTQ+ youth mental health (70). However, there remains a dearth of research on how we might tackle LGBTQ+ mental health inequality in schools. We need research to support the development of effective public mental health interventions both to support LGBTQ+ young people's mental health generally, but also as a step to undoing the devastating impact of COVID-19 on young people's mental health more broadly. This realist review sought to contribute to the current evidence base by developing a programme theory to understand how and why school-based interventions may prevent or reduce mental health problems in LGBTQ+ adolescents.

Further research is needed on school interventions to reduce LGBTQ+ mental health inequalities.

\section{Declarations}

\section{Competing interests}

- Not applicable.

\section{Ethics approval and consent to participate}

- Not applicable.

\section{Consent for publication}

- Not applicable.

\section{Availability of data and materials}

- Not applicable. 


\section{Funding}

- This work was funded by the National Institute for Health Research's (NIHR) School for Public Health Research's (SPHR) Public Mental Health programme (Funding Reference: PD-SPH-2015). The views expressed in this publication are those of the authors and not necessarily those of the NIHR or SPHR.

\section{Authors' contributions}

-E.M. lead the authorship of the main manuscript text, with substantive contributions and preparation of tables and figures by F.M., R.N., E.G-S., and L.S. All authors reviewed the manuscript.

\section{Acknowledgements}

- Not applicable.

\section{References}

1. McDermott E, Hughes E, Rawlings V. The social determinants of lesbian, gay, bisexual and transgender youth suicidality in England: a mixed methods study. Journal of Public Health. 2018;40(3):e244-e51.

2. Coker TR, Austin SB, Schuster MA. The health and health care of lesbian, gay, and bisexual adolescents. Annual review of public health. 2010;31:457-77.

3. Haas AP, Eliason M, Mays VM, Mathy RM, Cochran SD, D'Augelli AR, et al. Suicide and suicide risk in lesbian, gay, bisexual, and transgender populations: Review and recommendations. Journal of homosexuality. 2010;58(1):10-51.

4. Marshal MP, Dietz LJ, Friedman MS, Stall R, Smith HA, McGinley J, et al. Suicidality and depression disparities between sexual minority and heterosexual youth: A meta-analytic review. Journal of adolescent health. 2011;49(2):115-23.

5. Saewyc EM. Research on adolescent sexual orientation: Development, health disparities, stigma, and resilience. Journal of research on adolescence. 2011;21(1):256-72.

6. Irish M, Solmi F, Mars B, King M, Lewis G, Pearson RM, et al. Depression and self-harm from adolescence to young adulthood in sexual minorities compared with heterosexuals in the UK: A population-based cohort study. The Lancet Child \& Adolescent Health. 2019;3(2):91-8.

7. Di Giacomo E, Krausz M, Colmegna F, Aspesi F, Clerici M. Estimating the risk of attempted suicide among sexual minority youths: a systematic review and meta-analysis. JAMA pediatrics. 2018;172(12):1145-52.

8. Kamal K, Li JJ, Hahm HC, Liu CH. Psychiatric impacts of the COVID-19 global pandemic on US sexual and gender minority young adults. Psychiatry Research. 2021;299:113855. 
9. Hawke LD, Hayes E, Darnay K, Henderson J. Mental health among transgender and gender diverse youth: An exploration of effects during the COVID-19 pandemic. Psychology of Sexual Orientation and Gender Diversity. 2021.

10. Maxwell S, Reynolds KJ, Lee E, Subasic E, Bromhead D. The impact of school climate and school identification on academic achievement: Multilevel modeling with student and teacher data. Frontiers in psychology. 2017;8:2069.

11. Council NC. The school climate challenge: Narrowing the gap between school climate research and school climate policy, practice, guidelines and teacher education policy. Tersedia: https://www.schoolclimate org/themes/schoolclimate/ass ets/pdf/policy/school-climate-challengeweb pdf. 2007.

12. Brand S, Felner RD, Seitsinger A, Burns A, Bolton N. A large scale study of the assessment of the social environment of middle and secondary schools: The validity and utility of teachers' ratings of school climate, cultural pluralism, and safety problems for understanding school effects and school improvement. Journal of School Psychology. 2008;46(5):507-35.

13. Roeser RW, Eccles JS, Sameroff AJ. School as a context of early adolescents' academic and socialemotional development: A summary of research findings. The elementary school journal. 2000;100(5):443-71.

14. Brand S, Felner R, Shim M, Seitsinger A, Dumas T. Middle school improvement and reform: Development and validation of a school-level assessment of climate, cultural pluralism, and school safety. Journal of educational psychology. 2003;95(3):570.

15. Hudson-Sharp N, Metcalf H. Inequality among lesbian, gay bisexual and transgender groups in the UK: a review of evidence. London: National Institute of Economic and Social Research. 2016.

16. Peter T, Taylor C, Campbell C. "You can't break... when you're already broken": The importance of school climate to suicidality among LGBTQ youth. Journal of Gay \& Lesbian Mental Health. 2016;20(3):195-213.

17. Chances MY. Youth Chances summary of first findings: The experiences of LGBTQ young people in England. London: METRO. 2014.

18. Mackie G, Lambert K, Patlamazoglou L. The mental health of transgender young people in secondary schools: a scoping review. School mental health. 2021:1-15.

19. UNESCO. Out in the open: Education sector responses to violence based on sexual orientation and gender identity/expression. UNESCO Paris, France; 2016.

20. Mitchell M, Gray M, Beninger K. Tackling homophobic, biphobic and transphobic bullying among school-age children and young people. Evidence review and typology of initiatives London: Natcen. 2014.

21. Mitchell M, Kotecha M, Davies M, Porter H, Turley C. Evaluation of an anti-homophobic, biphobic and transphobic (HB\&T) bullying programme. National Centre for Social Research Available online at: http://natcen.ac.uk/media/1216039/natcens-independent-evaluation-of-an-anti-hbt-bullyingprogramme_research-report pdf [Google Scholar]. 2016. 
22. Aiden HS, Marston K, Perry T. Homophobic bullying: How well do we understand the problem? 2013.

23. Formby E. Limitations of focussing on homophobic, biphobic and transphobic 'bullying'to understand and address LGBT young people's experiences within and beyond school. Sex Education. 2015;15(6):626-40.

24. Gilbert J, Fields J, Mamo L, Lesko N. Intimate possibilities: The beyond bullying project and stories of LGBTQ sexuality and gender in US schools. Harvard Educational Review. 2018;88(2):163-83.

25. Ringrose J, Renold E. Normative cruelties and gender deviants: The performative effects of bully discourses for girls and boys in school. British educational research journal. 2010;36(4):573-96.

26. Black WW, Fedewa AL, Gonzalez KA. Effects of "Safe School" programs and policies on the social climate for sexual-minority youth: A review of the literature. Journal of LGBT youth. 2012;9(4):32139.

27. Wong G, Greenhalgh T, Westhorp G, Buckingham J, Pawson R. RAMESES publication standards: realist syntheses. BMC medicine. 2013;11(1):1-14.

28. Pawson R, Greenhalgh T, Harvey G, Walshe K. Realist review-a new method of systematic review designed for complex policy interventions. Journal of health services research \& policy. 2005;10(1_suppl):21-34.

29. Greenhalgh T, Wong G, Westhorp G, Pawson R. Protocol-realist and meta-narrative evidence synthesis: evolving standards (RAMESES). BMC medical research methodology. 2011;11(1):1-10.

30. Coryn C, Noakes L, Westine C, Schroter D. A Systematic Review of Theory-Driven Evaluation Practice From 1990 to 2009. American Journal of Evaluation. 2011;32(2):199-226.

31. Petticrew M. Time to rethink the systematic review catechism? Moving from 'what works' to 'what happens'.. Systematic Reviews 2015;4(1):36.

32. Harden SM, McEwan D, Sylvester BD, Kaulius M, Ruissen G, Burke SM, et al. Understanding for whom, under what conditions, and how group-based physical activity interventions are successful: a realist review. BMC public health. 2015;15.

33. Booth A, Papaioannou D, Sutton A. Systematic approaches to a successful literature review.. London: Sage; 2011.

34. Szalacha LA. Safer sexual diversity climates: Lessons learned from an evaluation of Massachusetts safe schools program for gay and lesbian students. American journal of education. 2003;110(1):5888.

35. Swanson K, Gettinger M. Teachers' knowledge, attitudes, and supportive behaviors toward LGBT students: Relationship to Gay-Straight Alliances, antibullying policy, and teacher training. Journal of LGBT youth. 2016;13(4):326-51.

36. Kull RM, Greytak EA, Kosciw JG, Villenas C. Effectiveness of school district antibullying policies in improving LGBT youths' school climate. Psychology of Sexual Orientation and Gender Diversity. 2016;3(4):407. 
37. McGuire JK, Anderson CR, Toomey RB, Russell ST. School climate for transgender youth: A mixed method investigation of student experiences and school responses. Journal of youth and adolescence. 2010;39(10):1175-88.

38. Snapp SD, Burdge H, Licona AC, Moody RL, Russell ST. Students' perspectives on LGBTQ-inclusive curriculum. Equity \& Excellence in Education. 2015;48(2):249-65.

39. Kohoulat N, Dehghani MR, Kohoulat N. Perceived school climate and students' mental health. International Journal of School Health. 2015;2(4):12-7.

40. Emmel N, Greenhalgh J, Manzano A, Monaghan M, Dalkin S. Doing realist research: Sage; 2018.

41. Jamal F, Fletcher A, Shackleton N, Elbourne D, Viner R, Bonell C. The three stages of building and testing mid-level theories in a realist RCT: a theoretical and methodological case-example. Trials. 2015;16(1):1-10.

42. Johnson K. Sexuality: A psychosocial manifesto: John Wiley \& Sons; 2015.

43. Meyer IH. Prejudice, social stress, and mental health in lesbian, gay, and bisexual populations: conceptual issues and research evidence. Psychological bulletin. 2003;129(5):674.

44. Hatzenbuehler ML. How does sexual minority stigma "get under the skin"? A psychological mediation framework. Psychological bulletin. 2009;135(5):707.

45. Riggs DW, Treharne GJ. Decompensation: A novel approach to accounting for stress arising from the effects of ideology and social norms. Journal of Homosexuality. 2017;64(5):592-605.

46. Cover R. Queer youth suicide, culture and identity: Unliveable lives?: Routledge; 2016.

47. McDermott E, Roen K. Queer youth, suicide and self-harm: troubled subjects, troubling norms: Springer; 2016.

48. Cooper C, Lhussier M, Shucksmith J, Carr SM. Protocol for a realist review of complex interventions to prevent adolescents from engaging in multiple risk behaviours. BMJ open. 2017;7(9):e015477.

49. Pawson R. Evidence-based policy: a realist perspective: sage; 2006.

50. Jagosh J, Pluye P, Macaulay AC, Salsberg J, Henderson J, Sirett E, et al. Assessing the outcomes of participatory research: protocol for identifying, selecting, appraising and synthesizing the literature for realist review. Implementation science. 2011;6(1):1-8.

51. Dalkin SM, Greenhalgh J, Jones D, Cunningham B, Lhussier M. What's in a mechanism? Development of a key concept in realist evaluation. Implementation science. 2015;10(1):1-7.

52. Rycroft-Malone J, McCormack B, Hutchinson AM, DeCorby K, Bucknall TK, Kent B, et al. Realist synthesis: illustrating the method for implementation research. Implementation Science. 2012;7(1):1-10.

53. Bopp PJ, Juday TR, Charters CW. A School-Based Program to Improve Life Skills and to Prevent HIV Infection in Multicultural Transgendered Youth in Hawai'i. Journal of Gay \& Lesbian Issues in Education. 2004;1(4):3-21.

54. Burk J, Park M, Saewyc EM. A media-based school intervention to reduce sexual orientation prejudice and its relationship to discrimination, bullying, and the mental health of lesbian, gay, and bisexual 
adolescents in Western Canada: A population-based evaluation. International journal of environmental research and public health. 2018;15(11):2447.

55. Craig SL, Austin A, McInroy LB. School-based groups to support multiethnic sexual minority youth resiliency: Preliminary effectiveness. Child and adolescent social work journal. 2014;31(1):87-106.

56. Goodenow C, Szalacha L, Westheimer K. School support groups, other school factors, and the safety of sexual minority adolescents. Psychology in the Schools. 2006;43(5):573-89.

57. Gunderson LM, Shattuck DG, Green AE, Vitous CA, Ramos MM, Willging CE. Amplification of schoolbased strategies resulting from the application of the dynamic adaptation process to reduce sexual and gender minority youth suicide. Implementation Research and Practice. 2021;2:2633489520986214.

58. Hatzenbuehler ML, Keyes KM. Inclusive anti-bullying policies and reduced risk of suicide attempts in lesbian and gay youth. Journal of Adolescent Health. 2013;53(1):S21-S6.

59. Hatzenbuehler ML, Birkett M, Van Wagenen A, Meyer IH. Protective school climates and reduced risk for suicide ideation in sexual minority youths. American journal of public health. 2014;104(2):27986.

60. Heck NC. Expanding, refining, and replicating research on high school gay-straight student alliances and sexual minority youth: University of Montana; 2013.

61. Heck NC. The potential to promote resilience: Piloting a minority stress-informed, GSA-based, mental health promotion program for LGBTQ youth. Psychology of Sexual Orientation and Gender Diversity. 2015;2(3):225.

62. Lapointe A, Crooks C. GSA members' experiences with a structured program to promote well-being. Journal of LGBT Youth. 2018;15(4):300-18.

63. Lindquist LM. School supports for LGBTQ students: Counteracting the dangers of the closet: University of Montana; 2016.

64. Poteat VP, Yoshikawa H, Calzo JP, Gray ML, DiGiovanni CD, Lipkin A, et al. Contextualizing GayStraight Alliances: Student, advisor, and structural factors related to positive youth development among members. Child development. 2015;86(1):176-93.

65. Poteat VP, Calzo JP, Yoshikawa H. Promoting youth agency through dimensions of gay-straight alliance involvement and conditions that maximize associations. Journal of Youth and Adolescence. 2016;45(7):1438-51.

66. Poteat VP, O'Brien MD, Rosenbach SB, Finch EK, Calzo JP. Depression, Anxiety, and Interest in Mental Health Resources in School-Based Gender-Sexuality Alliances: Implications for Sexual and Gender Minority Youth Health Promotion. Prevention Science. 2021;22(2):237-46.

67. Saewyc EM, Konishi C, Rose HA, Homma Y. School-based strategies to reduce suicidal ideation, suicide attempts, and discrimination among sexual minority and heterosexual adolescents in Western Canada. International journal of child, youth \& family studies: IJCYFS. 2014;5(1):89.

68. Sandfort TG, Bos HM, Collier KL, Metselaar M. School environment and the mental health of sexual minority youths: A study among Dutch young adolescents. American journal of public health. 
2010;100(9):1696-700.

69. Zhang L, Finan LJ, Bersamin M, Fisher DA. Sexual orientation-based depression and suicidality health disparities: The protective role of school-based health centers. Journal of research on adolescence. 2020;30:134-42.

70. Transforming children and young people's mental health provision: A green paper. Department of Health and Social Care; Department for Education; 2017.

\section{Figures}

Intervention Core Components

\section{Affirmative visual displays}

e.g. LGBT posters, rainbows

2.Sign posting to external sources of LGBT support

3.Standalone input e.g. assemblies, 'diversity days', 'role model' visits

\section{School-based LGBT} support groups

\section{Curriculum-based} delivery

\section{Staff training}

7. Inclusion policies e.g. anti-HBT bullying policy, named LGBT 'champion'
Theory of Change

Reduction of stigma

(Payne and Smith, 2011)

Increase in school connectedness, inclusion and belonging (Duong \&

Bradshaw, 2014)

Reduction of isolation and increase in peer support (Griffen et al. 2004)

Change in school culture through normalizing LGBT identities (Ploderl et al. 2010)

Reduction of LGBT

discrimination and

victimization (Meyer, 2003)
Mental Health Outcomes

Increase in self-esteem and self- acceptance (Difulvio 2011)

Decrease in low level psychiatric morbidity e.g. depression, anxiety (Baams et al. 2015)

Increase levels of confidence and wellbeing (Toomey et al., 2011)

Reduction in self-harm and suicidality (ideation and attempts)(Hatzenbuehler et al, 2014)

\section{Figure 1}

Initial Theory 
Figure 2. PRISMA diagram showing numbers of papers identified through searching
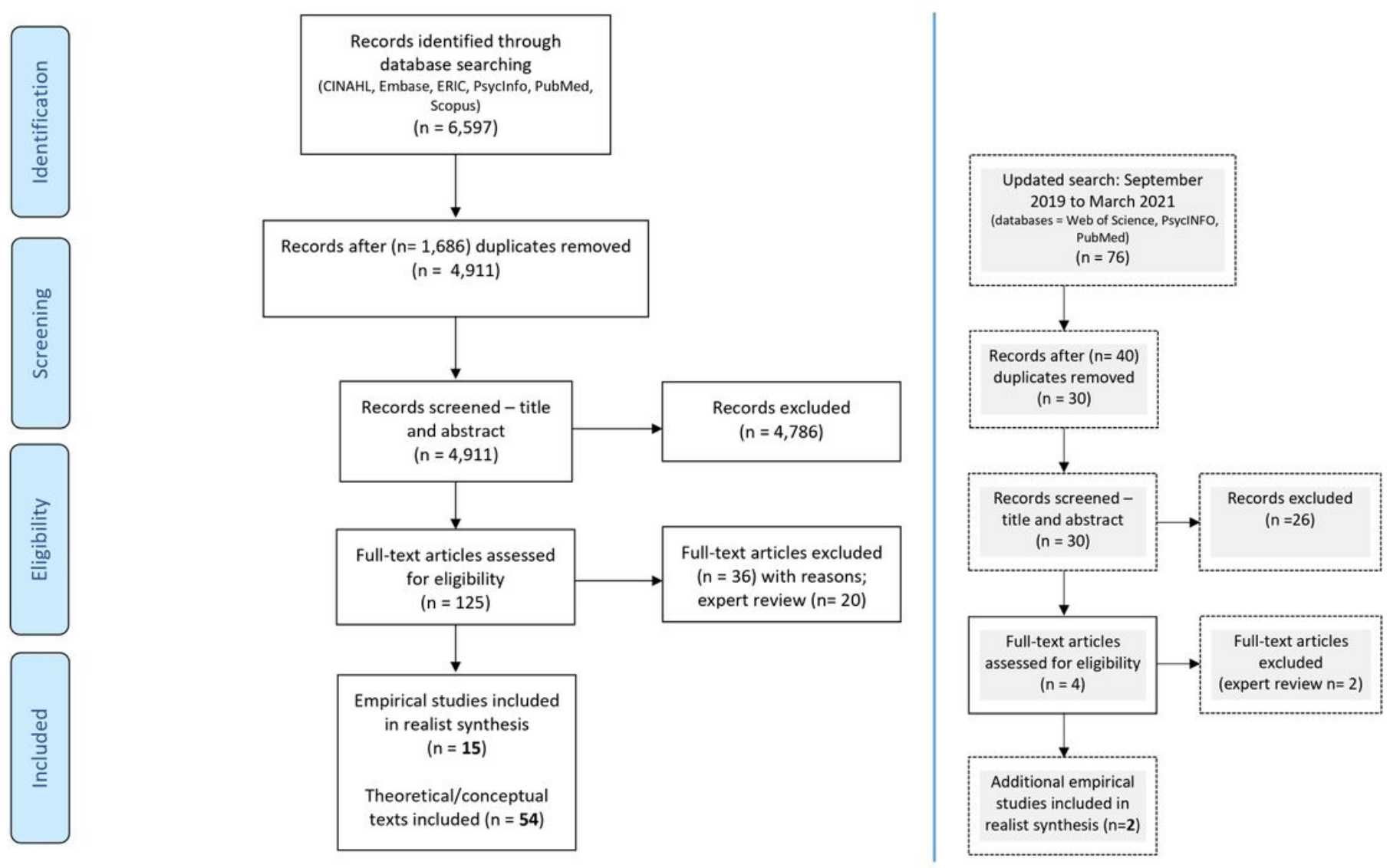

Figure 2

PRISMA diagram showing numbers of papers identified through searching 


\begin{tabular}{|c|c|c|c|c|}
\hline CONTEXT & $\begin{array}{l}\text { MECHANISM } 1 \\
\text { Intervention } \\
\text { Resources } \\
\end{array}$ & $\begin{array}{l}\text { MECHANISM } 2 \\
\text { Vector of change } \\
\text { What changes? }\end{array}$ & $\begin{array}{l}\text { MECHANISM } 3 \\
\text { Cognition } \\
\text { How does it change? }\end{array}$ & OUTCOME \\
\hline $\begin{array}{l}\text { School } \\
\text { culture } \\
\text { (gender and } \\
\text { sexuality) } \\
\text { LGBTQ++ } \\
\text { Champion } \\
\text { Legal, } \\
\text { Policy \& } \\
\text { Economic } \\
\text { Directives }\end{array}$ & $\begin{array}{l}\text { 1.Affirmative displays } \\
\text { 2.External signposting } \\
\text { (Hatzenbuehler, Birkett, } \\
\text { Wagenen, \& Meyer, } \\
\text { 2014; Heck, 2013) } \\
\text { 3.Stand alone (Burk, } \\
\text { park \& Saewyc, 2018) } \\
\text { 4.Support Groups (Bopp, } \\
\text { Juday \& Charters, 2004; } \\
\text { Craig, Austin \& } \\
\text { McInroy, 2014; } \\
\text { Goodenow, Szalacha, \& } \\
\text { Westheimer, 2006; } \\
\text { Gunderson et al, 2021; } \\
\text { Hatzenbuehler, Birkett, } \\
\text { Wagenen, \& Meyer, } \\
\text { 2014; Heck, 2013; Heck, } \\
\text { 2015; Lapointe \& } \\
\text { Crookss, 2018; Lindquist, } \\
\text { 2016; Poteat et al., 2015; } \\
\text { Poteat, Yoshikawa \& } \\
\text { Calzo, 2016; Poteat et } \\
\text { al., 2021; Saewyc et al., } \\
\text { 2014) } \\
\text { 5.Curriculum } \\
\text { (Gunderson et al., 2021; } \\
\text { Hatzenbuehler, Birkett, } \\
\text { Wagenen, \& Meyer, } \\
\text { 2014; Lindquist, 2016) }\end{array}$ & $\begin{array}{l}\text { 1. School } \\
\text { culture \& environment } \\
\text { (Goodenow, Szalacha, \& } \\
\text { Westheimer, 2006; } \\
\text { Gunderson et al, 2021; } \\
\text { Hatzenbuehler, Birkett, } \\
\text { Wagenen, \& Meyer, } \\
\text { 2014; Lindquist, 2016; } \\
\text { Sandfort et al., 2010) } \\
\\
\text { 2.Relationships \& } \\
\text { interactions (Bopp, Juday } \\
\text { \& Charters, 2004; Burk, } \\
\text { Park \& Saewyc, 2018; } \\
\text { Goodenow, Szalacha, \& } \\
\text { Westheimer, 2006; } \\
\text { Lapointe \& Crooks, } \\
\text { 2018; Lindquist, 2016) } \\
\\
\text { 3. Behaviours \& } \\
\text { actions (Bopp, Juday \& } \\
\text { Charters, 2004; } \\
\text { Goodenow, Szalacha, \& } \\
\text { Westheimer, 2006; } \\
\text { Gunderson et al, 2021; } \\
\text { Hatzenbuehler \& Keyes, } \\
\text { 2013; Hatzenbuehler, } \\
\text { Birkett, Wagenen, \& } \\
\text { Meyer, 2014; Heck, } \\
\text { 2013; Heck, 2015; } \\
\text { Poteat, Yoshikawa \& } \\
\text { Calzo, 2016; Saewyc et } \\
\text { al., 2014; Zhang et al., } \\
\text { 2020) }\end{array}$ & $\begin{array}{l}\text { Affirmation (I am } \\
\text { good) (Craig, Austin \& } \\
\text { McInroy, 2014; Lapointe } \\
\text { \& Crooks, 2018) } \\
\text { Agency (I can do) (Bopp, } \\
\text { Juday \& Charters, 2004; } \\
\text { Poteat, Yoghikawa \& } \\
\text { Calzo, 2016) } \\
\text { Advocacy (I can make } \\
\text { better) (Poteat, Yoshikawa } \\
\text { \& Calzo, 2016) } \\
\text { Belonging (I am } \\
\text { included) (Bopp, Juday \& } \\
\text { Charters, 2004; Lindquist, } \\
\text { 2016) } \\
\text { Connectedness (I am like } \\
\text { you) (Burk, Park \& } \\
\text { Saewyc, 2018) } \\
\text { Coping (I am } \\
\text { positive) (Bopp, Juday \& } \\
\text { Charters, 2004; Craig, } \\
\text { Austin \& McInroy, 2014; } \\
\text { Lapointe \& Crooks, 2018) } \\
\text { Recognition (I count) } \\
\text { Safety (I feel no fear) } \\
\end{array}$ & $\begin{array}{l}\text { Decrease in } \\
\text { poor MH } \\
\text { (Bopp, Juday } \\
\text { \& Charters, } \\
\text { 2004; Burk, } \\
\text { Park \& } \\
\text { Saewyc, 2018; } \\
\text { Craig, Austin } \\
\text { \& McInroy, } \\
\text { 2014; } \\
\text { Goodenow, } \\
\text { Szalacha, \& } \\
\text { Westheimer, } \\
\text { 2006; } \\
\text { Gunderson et } \\
\text { al., 2021; } \\
\text { Hatzenbuehler } \\
\text { \& Keyes, 2013; } \\
\text { Hatzenbuehler, } \\
\text { Birkett, } \\
\text { Wagenen, \& } \\
\text { Meyer, 2014; } \\
\text { Lindquist, } \\
2016 ; \text { poteat et } \\
\text { al., 2015; } \\
\text { Saewyc et al., } \\
2014 ; \text { Sandfort } \\
\text { at al., 2010; } \\
\text { Zhang et al., } \\
\text { 2020) } \\
\text { Increase in } \\
\text { factors } \\
\text { associated with }\end{array}$ \\
\hline & $\begin{array}{l}\text { 6.Staff training } \\
\text { (Goodenow, Szalacha, \& } \\
\text { Westheimer, 2006; } \\
\text { Gunderson et al, 2021; } \\
\text { Hatzenbuehler, Birkett, } \\
\text { Wagenen, \& Meyer, } \\
\text { 2014) } \\
\text { 7.Inclusion policies } \\
\text { (Goodenow, Szalacha, \& } \\
\text { Westheimer, 2006; } \\
\text { Gunderson et al, 2021; } \\
\text { Hatzenbuehler \& Keyes, } \\
\text { 2013; Hatzenbuehler, } \\
\text { Birkett, Wagenen, \& } \\
\text { Meyer, 2014; Lindquist, } \\
\text { 2016; Saewyc et al, } \\
\text { 2014) } \\
\text { 8.Talking to trusted } \\
\text { adult (Bopp, Juday \& } \\
\text { Charters, 2004; Craig, } \\
\text { Austin \& McInroy, 2014; } \\
\text { Goodenow, Szalacha, \& } \\
\text { Westheimer, 2006; } \\
\text { Gunderson et al, 2021; } \\
\text { Lindquigt, 2016; Zhang } \\
\text { at al., 2020) }\end{array}$ & $\begin{array}{l}\text { 4. Self, thoughts, } \\
\text { beliefs (Bopp, Juday \& } \\
\text { Charters, 2004; Craig, } \\
\text { Austin \& McInroy, 2014; } \\
\text { Lapointe \& Crooks, } \\
\text { 2018; Poteat et al., 2015) } \\
\text { 5. Affect, feeling, } \\
\text { emotions (Bopp, Juday } \\
\text { \& Charters, 2004; Burk, } \\
\text { Park \& Saewyc, 2018; } \\
\text { Craig, Austin \& } \\
\text { McInroy, 2014; } \\
\text { Goodenow, Szalacha, \& } \\
\text { Westheimer, 2006; } \\
\text { Gunderson et al, 2021; } \\
\text { Hatzenbuehler \& Keyes, } \\
\text { 2013; Hatzenbuehler, } \\
\text { Birkett, Wagenen, \& } \\
\text { Meyer, 2014; Heck, } \\
\text { 2015; Lapointe \& } \\
\text { Crooks, 2018; Lindquist, } \\
\text { 2016; Poteat et al., 2015; } \\
\text { Poteat et al., 2021; } \\
\text { Saewyc et al., 2014; } \\
\text { Zhang et al., 2020) } \\
\end{array}$ & $\begin{array}{l}\text { Usualising (I am } \\
\text { accepted) (Bopp, Juday \& } \\
\text { Charters, 2004) } \\
\end{array}$ & $\begin{array}{l}\text { +MH } \\
\text { (Goodenow, } \\
\text { Szalacha, \& } \\
\text { Westheimer, } \\
\text { 2006; Heck, } \\
\text { 2015; Lapointe } \\
\text { \& Crooks, } \\
\text { 2018; Poteat, } \\
\text { Yoghikawa \& } \\
\text { Calzo, 2016; } \\
\text { Poteat et al., } \\
\text { 2021) }\end{array}$ \\
\hline
\end{tabular}

Figure 3

Programme Theory

\section{Supplementary Files}

This is a list of supplementary files associated with this preprint. Click to download. 
- Appendix1Searchterms.docx

- Appendix2StudyCharacteristics.docx 